\title{
CONSIDERAÇÕES SOBRE A MORFOLOGIA FOLIAR DE BLEPHAROCALYX SALICIFOLIUS (H.B.K.) BERG NO RIO GRANDE DO SUL ${ }^{1}$
}

\author{
LUCIANO DENARDI² JOSÉ NEWTON CARDOSO MARCHIORI ${ }^{3}$
}

\section{RESUMO}

Blepharocalyx salicifolius (H.B.K.) Berg apresenta notável plasticidade morfológica, especialmente na forma e dimensões das folhas. Além do reconhecimento dessa variabilidade, o presente trabalho busca analisar seu real significado ecológico.

Palavras-chave: Blepharocalyx salicifolius, morfologia foliar, Rio Grande do Sul.

\section{ABSTRACT}

Blepharocalyx salicifolius (H. B. K.) Berg shows a remarkable variability, especially in the shape and size of leaves. Aside the recognition of this variability, this paper deals to analyze its real ecological significance. Key words: Blepharocalyx salicifolius, leaf morphology, Rio Grande do Sul.

\section{INTRODUÇÃO}

Pertencente à família Myrtaceae e conhecida popularmente por "murta", Blepharocalyx salicifolius (H.B.K.) Berg é uma árvore de porte pequeno até grande, com ampla distribuição geográfica no Rio Grande do Sul e notável variabilidade morfológica, motivo de sua rica sinonímia na literatura botânica. Restrita à América do Sul, sua área de distribuição estende-se de Goiás ao Uruguai, ocorrendo ainda no Paraguai, Argentina (de Buenos Aires até Jujuy), Bolívia e Equador (Cozzo, 1956; Landrum, 1986; Lorenzi, 1998). No Rio Grande do Sul, a distribuição da murta inclui praticamente toda a área de ocorrência do pinheiro brasileiro, além da Serra do Sudeste (Canguçú, Dom Feliciano, Santana da Boa Vista, Piratini) e da Campanha do Sudoeste, sobretudo na bacia dos rios Santa Maria e Quaraí (Reitz et al., 1988).

Na Floresta Ombrófila Mista, as árvores distinguem-se pelas folhas largas e dimensão avantajada dos troncos. Na Serra do Sudeste e Campanha do Sudoeste, ao contrário, os indivíduos são de pequeno porte, correspondendo a arvoretas de tronco geralmente tortuoso e fo- lhas linear-lanceoladas (Marchiori \& Sobral, 1997). Esse notável polimorfismo é que levou autores, como Legrand (1936), Tortorelli (1956), Legrand \& Klein (1978) e Reitz et al. (1988), entre outros, a reconhecerem diferentes espécies, variedades e formas botânicas. De acordo com Landrum (1986), que investigou a murta em toda a sua área de ocorrência, as descontinuidades verificadas entre indivíduos não justificam a segregação da mesma em espécies distintas, motivo pelo qual mais de 60 binômios foram por ele reduzidos à sinonímia de Blepharocalyx salicifolius (H.B.K.) Berg.

$\mathrm{O}$ pensamento taxonômico predominante na atualidade, bem como a estrutura da madeira, investigada por Denardi (2004), inclinam-se favoravelmente à interpretação de Landrum (1986), apontando para a existência de uma única espécie de Blepharocalyx na flora sul-brasileira.

\section{MATERIAL E MÉTODOS}

\section{Caracterização dos pontos de coleta}

O material botânico estudado procede de duas regiões no Rio Grande do Sul: a Serra do Sudeste e os Campos de Cima da Serra.

1 Artigo recebido em 20/11/2004 e aceito para a publicação em 15/03/2005.

2 Engenheiro Florestal, Msc., Acadêmico do Programa de Pós-Graduação em Engenharia Florestal, Centro de Ciências Rurais, Universidade Federal de Santa Maria, CEP 97105-900, Santa Maria (RS). lucianodenardi@yahoo.com.br

${ }^{3}$ Engenheiro Florestal, Dr., Professor Titular do Departamento de Ciências Florestais, Centro de Ciências Rurais, Universidade Federal de Santa Maria, CEP 97105-900, Santa Maria (RS). balduinia@mail.ufsm.br 
$\mathrm{Na}$ Serra do Sudeste, escolheu-se como ponto de coleta a localidade de Guaritas, cerca de 50 $\mathrm{Km}$ da cidade de Caçapava do Sul. O relevo, de forte-ondulado a montanhoso, oscila entre 100 e 400 metros de altitude. Os solos, litólicos e eutróficos, compõem a Associação Guaritas Afloramentos de Rocha; bastante rasos, arenosos e bem drenados, eles têm pequena capacidade de retenção de água e são pobres em nutrientes (Lemos et al., 1973). A vegetação, classificada como Savana-Parque (Leite \& Klein, 1990), apresenta amplas áreas com elemento arbóreo rarefeito, ao lado de outras com agrupamentos consideráveis de árvores e arvoretas.

Na região fisiográfica dos Campos de Cima da Serra, usou-se como local de coleta a Floresta Nacional de São Francisco de Paula, situada cerca de $27 \mathrm{~km}$ da sede do município de mesmo nome. Assentada em planalto de origem basáltica, com altitudes entre 900 e $1.200 \mathrm{~m}$, a região é marcada por coxilhas de declives curtos. O solo, classificado como Cambisol Húmico, é em geral profundo, argiloso, moderadamente drenado e rico em matéria orgânica, não havendo falta d'água devido à alta precipitação pluviométrica, característica da região, e à elevada capacidade de retenção de umidade do solo (Lemos et al., 1973). A vegetação nativa é classificada como Floresta Ombrófila Mista (Leite \& Klein, 1990).

De acordo com Moreno (1961), tanto a Serra do Sudeste como os Campos de Cima da Serra enquadram-se no mesmo tipo climático $-\mathrm{Cfb}$ 1, de Köppen -, apresentando temperatura de 16,8 e $14,4^{\circ} \mathrm{C}$ e precipitação média anual de 1.665 e $2.468 \mathrm{~mm}$, respectivamente.

\section{Coleta de material botânico}

Em cada região, foram coletadas folhas de três exemplares adultos da espécie, em diferentes posições da copa. Foram selecionadas 80 folhas por indivíduo, descartando-se as do ápice de ramos ou em fase de crescimento. Folhas quebradas, dobradas ou com anomalias, foram igualmente desconsideradas.
As exsicatas do material coletado foram incorporadas ao Herbário do Departamento de Ciências Florestais da Universidade Federal de Santa Maria (HDCF), com os seguintes registros: HDCF 4336, 4337, 4338 (Serra do Sudeste); 4331, 4339, 4340 (Campos de Cima da Serra).

\section{Mensuração e descrições foliares}

Para cada folha, foram medidos ou determinados: o comprimento e a largura da lâmina, o comprimento do pecíolo e a área foliar; cabe informar, todavia, que para esta última característica, por ser mais trabalhosa, valeu-se de apenas metade das folhas selecionadas. Com base nas medições, determinou-se, ainda, a proporção comprimento/largura da lâmina. As comparações de médias entre procedências valeramse do Teste "t", de Fisher (Vieira, 1999). As descrições foliares baseiam-se em caracteres usuais na literatura botânica.

\section{RESULTADOS E DISCUSSÕES}

\section{Aspectos gerais da morfologia foliar}

A murta apresenta folhas simples, opostas, inteiras e de consistência membranácea. Providas de rala pilosidade, com nervura principal impressa na face superior e saliente na inferior, as folhas possuem densa nervação secundária, em ângulos de $45-60^{\circ} \mathrm{com}$ a principal, além de glândulas translúcidas, que exalam odor característico ao serem esmagadas. A lâmina foliar, de 1,8-6,5 cm de comprimento por 0,2-1,9 cm de largura, varia, segundo a procedência, de linear-lanceolada, com ápice e base agudos, até lanceolada, com ápice geralmente caudado (Figura 1a,b). O pecíolo, piloso, mede de 0,2 a 1,3 $\mathrm{cm}$ de comprimento. A área foliar varia de $0,6-$ $6,8 \mathrm{~cm}^{2}$, e a proporção comprimento/largura da lâmina, de 2,7/1 a 14,8/1.

A presença de glândulas translúcidas e o odor característico das folhas, embora pouco comentados na literatura botânica, são aspectos valiosos para a identificação dendrológica, devido ao número expressivo de Mirtáceas na flora sul- 


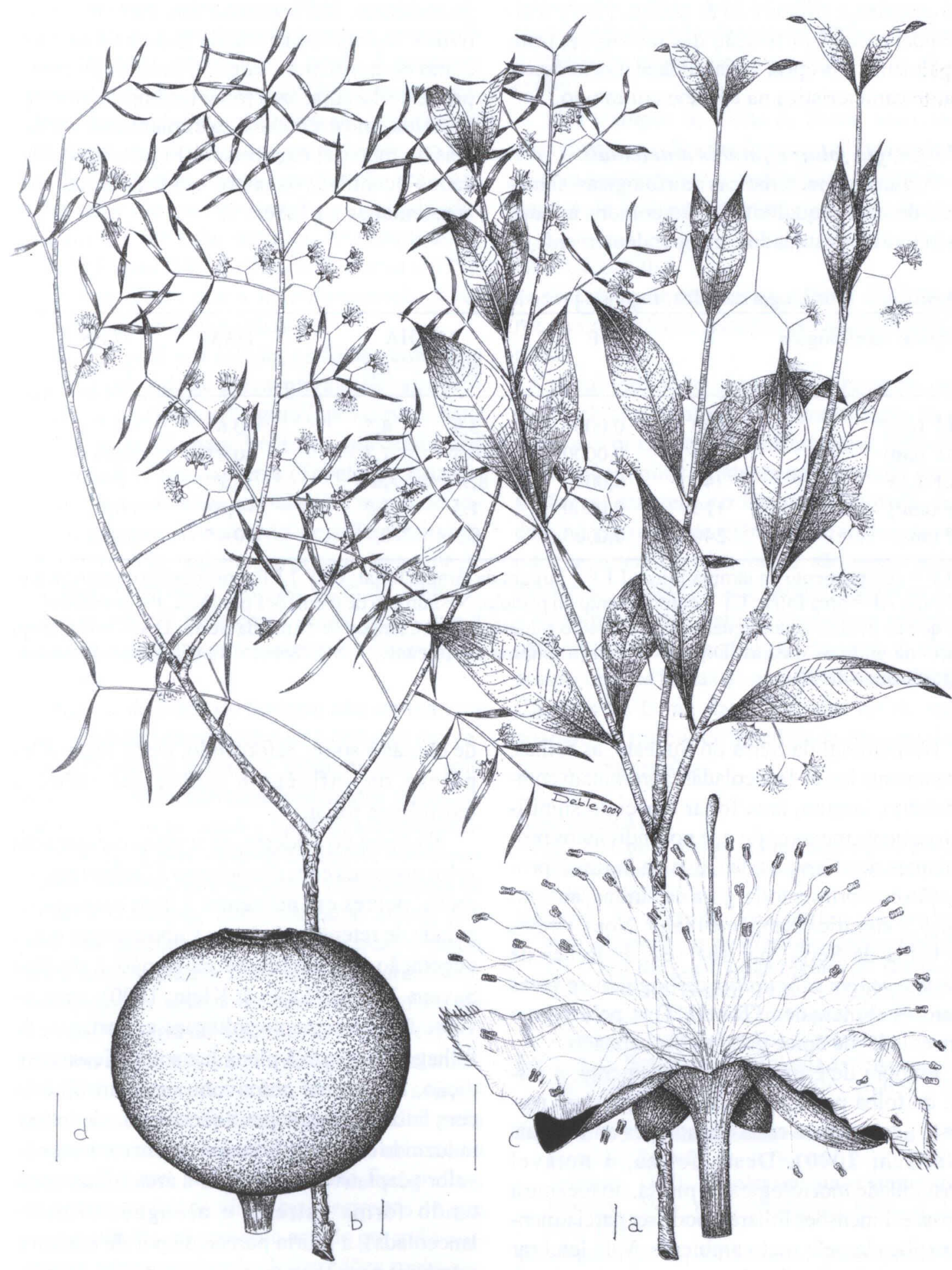

FIGURA 1 - Detalhes morfológicos de Blepharocalyx salicifolius: a, folhas lanceoladas de ápice caudado (Campos de Cima da Serra); b, folhas linear-lanceoladas (Serra do Sudeste); c,d, aspectos de flores e frutos. 
rio-grandense (Marchiori \& Sobral, 1997), à dificuldade de identificação das mesmas e, principalmente, à própria variabilidade morfológica, muito característica na espécie em estudo.

\section{Morfologia foliar e fatores ambientais}

Algumas características morfológicas, sobretudo de ordem qualitativa, são comuns a todos os indivíduos estudados, independentemente da procedência. Em contrapartida, aspectos relativos à forma e dimensão da lâmina foliar, tais como comprimento, largura, proporção comprimento/largura, área foliar e comprimento de pecíolos, mostraram-se extremamente variáveis no material examinado (Figura 1a,b). Os dados quantitativos sobre estes aspectos são apresentados na Tabela 1 .

TABELA 1: Morfologia da folha, segundo procedência.

\begin{tabular}{lcccccc}
\hline \multirow{2}{*}{ Aspecto morfológico } & \multirow{2}{*}{$\mathrm{N}$} & $\mathrm{P}$ & \multicolumn{2}{c}{ MÉDIA } & DAM & DMS \\
& & & $\mathrm{SS}$ & $\mathrm{CS}$ & & $(+/-)$ \\
\hline CLF $(\mathrm{cm})$ & 240 & 0,0000 & 3,9 & 4,5 & $-0,6^{*}$ & 0,1 \\
LLF $(\mathrm{cm})$ & 240 & 0,0000 & 0,5 & 1,3 & $-0,8^{*}$ & 0,03 \\
CLF/LLF & 240 & 0,0000 & $8,9 / 1$ & $3,6 / 1$ & $5,3^{*}$ & 0,3 \\
$\mathrm{AF}\left(\mathrm{cm}^{2}\right)$ & 120 & 0,0000 & 1,3 & 3,2 & $-1,9^{*}$ & 0,2 \\
$\mathrm{CP}(\mathrm{cm})$ & 240 & 0,0000 & 0,3 & 0,7 & $-0,4^{*}$ & 0,003 \\
\hline
\end{tabular}

$\mathrm{CLF}=$ comprimento da lâmina foliar; $\mathrm{LLF}$ = largura da lâmina foliar; $\mathrm{CLF} / \mathrm{LLF}=$ proporção comprimento/ largura; $\mathrm{AF}$ = área foliar; $\mathrm{CP}=$ comprimento do pecíolo; $\mathrm{N}=$ número de medições por local; $\mathrm{P}=$ probabilidade de que as médias sejam iguais; $\mathrm{SS}=$ Serra do Sudeste; $\mathrm{CS}=$ Campos de Cima da Serra; DAM = diferença absoluta entre as médias; DMS = diferença mínima significante; * = diferença significativa ao nível de significância de $5 \%$.

No material da Serra do Sudeste, as folhas, tipicamente linear-lanceoladas, apresentam comprimento, largura, área foliar e pecíolo significativamente menores do que nos indivíduos procedentes dos Campos de Cima da Serra. A proporção comprimento/largura da lâmina, ao contrário, é significativamente maior. Nos Campos de Cima da Serra, por sua vez, as folhas de Blepharocalyx salicifolius distinguem-se pelas maiores dimensões (Tabela 1) e pela forma lanceolada, de ápice geralmente caudado.

Embora determinada geneticamente, a forma da folha pode sofrer modificações em resposta adaptativa a certas condições ambientais (Nultsch, 2000). Dessa forma, a notável plasticidade morfológica da murta, no tocante à forma e dimensões foliares, pode ser parcialmente explicada pelo meio ambiente. Vale lembrar que a espécie, distribuída em vasta área na América do Sul (Cozzo, 1956; Landrum, 1986; Lorenzi, 1998), ocorre nos mais variados tipos de climas e solos, reforçando, ainda mais, a hipótese da influência ambiental sobre a morfologia foliar.

$\mathrm{Na}$ Serra do Sudeste, as árvores crescem em solos arenosos com abundantes afloramentos de rocha, pobres em nutrientes e com baixa capacidade de retenção de água. Cabe agregar que a vegetação predominante na região é do tipo Savana-Parque (Leite \& Klein, 1990), com árvores freqüentemente solitárias e, portanto, de folhagem exposta à plena luz solar. Nessa condição, as árvores convivem simultaneamente com falta d'água e super-aquecimento de folhas, induzindo o desenvolvimento de mecanismos de valor adaptativo. Ao reduzir a área foliar, mantendo forma estreita e alongada (linearlanceolada), a murta parece dispor de eficiente estratégia para contrapor-se tanto ao super-aquecimento das folhas, como à perda excessiva de água por evapotranspiração. 
De acordo com Ferri (1993), a redução da superfície foliar constitui-se no mecanismo mais eficiente para minimizar a perda d'água em ambientes secos. Givnish (1979), por sua vez, constatou que folhas pequenas são próprias de ambientes secos, ensolarados e pobres em nutrientes, enquanto folhas grandes são mais comuns em áreas quentes, com boa disponibilidade hídrica e luz solar indireta. As pesquisas de Leite \& Lieras (1978) e Medri \& Lieras (1979), também indicam que a maior exposição à luz tende a reduzir a área foliar.

No material em estudo, as folhas coletadas na Serra do Sudeste apresentaram elevada proporção comprimento/largura (aproximadamente 9/1), baixando para 3,6/1 nos indivíduos dos Campos de Cima da Serra (Tabela 1). Esta redução é amplamente reconhecida como de valor adaptativo. De acordo com Parkhurst \& Loucks (1972), folhas com proporção acima de $4 / 1$, tais como observado na Serra do Sudeste, são comuns em ambientes secos, posto que a forma alongada permite amenizar o super-aquecimento.

Apesar da Serra do Sudeste não ser uma região verdadeiramente xérica $(1.665 \mathrm{~mm}$ de precipitação média anual), é evidente que o solo arenoso e os constantes afloramentos de rocha, característicos na região, limitam a disponibilidade de água para as árvores, repercutindo nas dimensões foliares e na estrutura anatômica da madeira (Denardi, 2004). Mesmo assim, não pode ser definida, com certeza, qual a causa determinante para a redução da lâmina foliar, pois o caráter resulta da interação de diversos fatores. Na Serra do Sudeste, as árvores experimentam eventual carência de água e nutrientes, devido à natureza dos solos, bem como superaquecimento das folhas, maximizadas pelo distanciamento dos indivíduos, característico na Savana-Parque. Na mesma região fisiográfica, observam-se folhas ainda mais estreitas do que as examinadas no presente estudo em indivíduos que habitam a borda de paredões rochosos, ao passo que folhas largas não são raras em árvores que crescem junto a riachos, onde o solo é mais profundo, úmido e com conteúdo aparentemente elevado de matéria orgânica, aspecto também reportado por Guadagnin et al. (1999).

Nos Campos de Cima da Serra, sob condições diversas, a lâmina foliar usualmente alcança área maior e menor proporção comprimento/ largura, indicando ambiente não estressante.

\section{CONCLUSÕES}

$\mathrm{O}$ estudo da morfologia foliar de Blepharocalyx salicifolius permite as seguintes conclusões:

- A variabilidade comprovada no presente estudo dificulta a identificação dendrológica da espécie e explica, pelo menos em parte, a diversidade de binômios existente na literatura. A consistência, margem do limbo, pilosidade, bem como a presença de glândulas translúcidas e o odor característico das folhas, são aspectos fundamentais à identificação prática da mesma; - As folhas curtas, estreitas e de área reduzida, observadas em indivíduos da Serra do Sudeste, assim como as folhas de maiores dimensões, dos Campos de Cima da Serra, têm nítido valor adaptativo, refletindo a realidade ambiental das respectivas regiões.

\section{BIBLIOGRAFIA}

Cozzo, D. Como utilizar la madera de los árboles cultivados. Buenos Aires: Editorial Comopolita, p.103-104, 1956.

Denardi, L. Estudo anatômico do lenho e morfologia foliar de Blepharocalyx salicifolius (H.B.K.) Berg, em duas regiões do Rio Grande do Sul. Rio Grande do Sul: UFSM, 2004. 94f. Dissertação (Mestrado em Engenharia Florestal) - Universidade Federal de Santa Maria.

Ferri, M. G. Botânica: Morfologia externa das plantas (Organografia). São Paulo: Nobel, 1993. 149p.

Givnish, T. J. On the adaptative significance of leaf form. In: Solbrig, O. T., Raven, P. H., Jain, S., Johnson, G. B., Topics in plant population biology. New York: University Press, p. 375407, 1979.

Guadagnin, D. L., Larocca, J., Sobral, M. Flora vascular de interesse para a conservação da Bacia do Arroio João Dias: Avaliação ecológica rápida. In: As minas do Camaquã: um estudo 
multidisciplinar. São Leopoldo: Unisinos, p. 7184, 1999.

Landrum, L. R. Campomanesia, Pimenta, Blepharocalyx, Legrandia, Acca, Myrrhinium, and Luma (Myrtaceae). Flora Neotropica, n. 45, p. 116-160, 1986.

Legrand, D. Las mirtáceas del Uruguay. Anales del Museo de Historia Natural de Montevideo, v. 4, n. 11, p. 25-33, 1936.

Legrand, C. D., Klein, R. M. Mirtáceas. 17. Myrciaria, 18. Pseudocaryophyllus, 19. Blepharocalyx, 20. Espécies suplementares, 21. Espécies cultivadas, 22. Generalidades. In: Reitz, P. R. Flora Ilustrada Catarinense. Itajaí: Herbário Barbosa Rodrigues, p. 731-876, 1978.

Leite, A. Ma. C., Lieras, E. Ecofisiologia de plantas da Amazônia - Anatomia foliar e ecofisiologia de Pogonophora schomburgkiana Miers. (Euphorbiace). Acta Amazonica, v. 8, n. 3, p. 365-370, 1978.

Leite, P. F., Klein, R. M. Vegetação. In: Geografia do Brasil: Região Sul. Rio de Janeiro: IBGE, 1990. 420p.

Lemos, R. C., Azolin, M. A. D., Abraão, P. V. R.; et al. Levantamento e reconhecimento dos solos do Estado do Rio Grande do Sul. Recife: Ministério da Agricultura, Departamento Nacional de Pesquisas Agropecuárias - Divisão de Pesquisas Pedológicas, 1973. 431p.
Lorenzi, H. Árvores brasileiras: Manual de identificação e cultivo de plantas arbóreas nativas do Brasil. Nova Odessa: Editora Plantarum, 1998. p. 244.

Marchiori, J. N. C., Sobral, M. Dendrologia das angiospermas: Myrtales. Santa Maria: Ed. da UFSM, 1997. 304p.

Medri, M. E., Lieras, E. Ecofisiologia de plantas da Amazônia - Anatomia foliar e ecofisiologia de Bertholletia excelsa Humb. \& Bonpl. (Castanhado-Pará) - Lecythidaceae. Acta Amazonica,v. 9, n. 1, p. 15-23, 1979.

Medri, M. E., Lieras, E. Aspectos da anatomia ecológica de folhas de Hevea brasiliensis Müll. Arg. Acta Amazonica, v. 10, n. 3, p. 463-493, 1980.

Moreno, J. A. Clima do Rio Grande do Sul. Porto Alegre: Secretaria da Agricultura - RS, 1961. $41 \mathrm{p}$.

Nultsch, W. Botânica Geral. Porto Alegre: Artes Médicas Sul, p. 191- 202, 2000.

Parkhurst, D. F, Loucks, O. L. Optimal leaf size in relation to environment. Journal of Ecology, v. 60, p. 505-537, 1972.

Reitz, R., Klein, R. M., Reis, A. Projeto Madeira do Rio Grande do Sul. Porto Alegre: Sudesul, 1988. 525p.

Tortorelli, L. A. Maderas y Bosques Argentinos. Buenos Aires: ACME, p. 564-567, 1956.

Vieira, S. Estatística experimental. São Paulo: Atlas, 1999. 185p. 